\title{
The application of antimicrobial peptides as growth and health promoters for swine
}

\author{
Hao Xiao ${ }^{1,2}$, Fangyuan Shao ${ }^{1}$, Miaomiao $\mathrm{Wu}^{3}$, Wenkai Ren ${ }^{1,2}$, Xia Xiong ${ }^{1}$, Bie Tan ${ }^{{ }^{*}}$ and Yulong Yin ${ }^{1,4^{*}}$
}

\begin{abstract}
With the widespread ban on the use of antibiotics in swine feed, alternative measures need to be sought to maintain swine health and performance. Antimicrobial peptides (AMPs) are part of the nonspecific defense system and are natural antibiotics produced by plants, insects, mammalians, and micro-organisms as well as by chemical synthesis. Due to their broad microbicidal activity against various fungi, bacteria and enveloped viruses, AMPs are a potential alternative to conventional antibiotics for use in swine production. This review focuses on the structure and mechanism of action of AMPs, as well as their effects on performance, immune function and intestinal health in pigs. The aim is to provide support for the application of AMPs as feed additives replacing antibiotics in swine nutrition.
\end{abstract}

Keywords: Antimicrobial peptides, Antibiotics, Applications, Swine

\section{Background}

Antibiotics have been used in the swine industry for more than 50 years to improve growth and prevent infectious diseases. However, the misuse of antibiotics has caused many problems including the emergence of bacteria resistant to antibiotics and the potential of producing drug residues in meat products [1]. As a result, a global trend has emerged towards restriction of the inclusion of antibiotics in swine diets as a routine means of growth promotion. In response, a considerable amount of research has been focused on the development of alternatives to antibiotics to maintain swine performance and health.

Antimicrobial peptides (AMPs) are one of the most widely researched alternatives to conventional antibiotics. AMPs are potent, broad spectrum antibiotics which have been demonstrated to kill gram-negative and gram-positive bacteria, mycobacteria, viruses, fungi and even transformed or cancerous cells while having no effect on the cells of treated animals [2]. In recent years, studies on AMPs and their applications have become

\footnotetext{
* Correspondence: bietan@isa.ac.cn; yinyulong@isa.ac.cn

'Observation and Experiment Station of Animal Nutrition and Feed Science in South-Central China, Ministry of Agriculture, Hunan Provincial Engineering Research Center for Healthy Livestock and Poultry Production, Key Laboratory of Agro-ecological Processes in Subtropical Region, Institute of Subtropical Agriculture, Chinese Academy of Sciences, Changsha, Hunan 410125, China Full list of author information is available at the end of the article
}

one of the hot spots in the areas of agricultural science, biology, medicine, and physiology as well as having potential applications in medicine and the food industry.

Supplementation with various antimicrobial peptides has been reported to have positive effects on performance, nutrient digestibility, the intestinal microflora, intestinal morphology and immune function in pigs [3-5]. This article provides an overview of AMPs, their categories and structure, mechanism of action and their potential applications in swine production.

\section{Structure and categories of antimicrobial peptides}

AMPs are oligopeptides with a variable composition of amino acids and amino acid number (typically 6 to 100 amino acids). Based on the different sources, AMPs are divided into mammalian AMPs (e.g. defensin), amphibian AMPs (e.g. magainins), insect AMPs (e.g. cecropin), plant AMPs (e.g. thionin), and microbial AMPs (e.g. gramicidin and nisin). Based on their biological activities, AMPs can also be divided into antiviral peptides (e.g. defensins, and NP-1), antibacterial peptides (e.g. nisin, and pyrrhocoricin), antifungal peptides, and antiparasitic peptides [6].

AMPs are small, positively charged, amphipathic molecules which possess both hydrophobic and hydrophilic regions. Based on their secondary structure, AMPs are characterized as one of four types including $\alpha$-helical, $\beta$ - 
sheet (due to the presence of 2 or more disulfide bonds), alpha-beta and non-alpha-beta structure [7]. Because they consist solely of amino acids, it is very easy to modify the structure of AMPs. Chemical synthesis or recombinant expression systems can be used to produce fully synthetic peptides [6].

\section{Mechanism of antimicrobial activity of antimicrobial peptides}

It has been suggested that the interaction and action of AMPs with target cells depends on the two factors: the cell surface which is the classic and large acting mechanism and the amino acid composition of AMPs [8]. Furthermore, researchers have found that there have two main kinds of AMPs namely membrane-active AMPs and intracellularactive AMPs (Figure 1).

\section{Membrane-active antimicrobial peptides}

In order to explain membrane disruption by AMPs, researchers have proposed many models including the "barrel-stave", "toroidal", "carpet" and "aggregate channel” models. Early in 1977, Ehrenstein and Lecar [9] proposed the "barrel-stave model" which suggests that peptides directly insert into the lipid core of the target membrane to form trans-membrane pores. In the "toroidal model", peptide molecules are inserted into the membrane forming a bundle, inducing the lipid monolayers to continuously bend through the pore [9]. The "carpet model", suggests that AMPs use a detergent- like action to cover the membrane surface in order to affect its architecture $[10,11]$. In the "aggregate channel model", the peptides insert into the membrane and then cluster into unstructured aggregates that span the membrane. These aggregates are proposed to have water molecules associated with them providing channels for leakage of ions and possibly larger molecules through the membrane [12] (Figure 1).

\section{Intracellular-active antimicrobial peptides}

Cell membrane permeabilization by AMPs was thought to be the primary mechanism of killing. However, there is increasing evidence to prove that some AMPs can interact with an array of intracellular targets including DNA, RNA and protein to kill their target cells, but not damage the cell membrane. AMPs can directly prevent DNA, RNA and protein synthesis, as well as cell wall synthesis and proteases of microbes by means of direct penetration and endocystosis to enter the cells [13] (Figure 1). For example, PR-39 from pig intestines can act like a proteolytic agent and suppress protein and DNA synthesis to kill bacteria [14], while seminaplasmin can inhibit RNA polymerase and stop RNA synthesis completely at very low concentrations [15].

\section{The applications of antimicrobial peptides in swine nutrition}

Some AMPs, including antimicrobial peptide A3, P5, colicin E1, cecropin AD, and cipB-lactoferricin-lactoferrampin

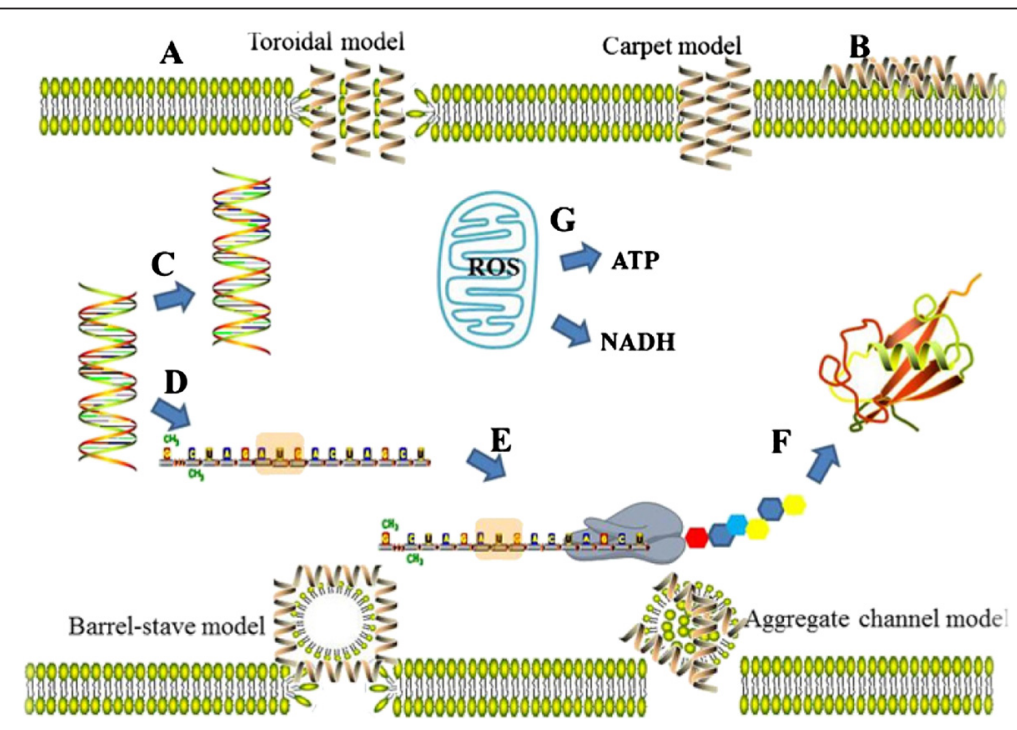

Figure 1 The diverse mechanistic modes of action for antimicrobial peptides. The figure means two main kinds of AMPs namely membrane-active AMPs and intracellular-active AMPs. The mechanism of membrane-active AMPs includes the "barrel-stave", "toroidal", "carpet" and "aggregate channel" models (A); B-G means the mechanism of intracellular-active AMPs. A, membrane activity contains Toroidal model, Carpet model, Barrel-stave model and Aggregate channel model; B, Inhibition of enzymes necessary for linking of cell wall structural proteins; $\mathbf{C}$, Inhibition of DNA synthesis; $\mathbf{D}$, Inhibition of RNA synthesis; E, Inhibition of ribosomal function and protein synthesis; $\mathbf{F}$, Blocking of chaperone proteins necessary for proper folding of proteins; G, inhibition of cellular respiration and induction of ROS formation and damage of mitochondrial cell membrane integrity and efflux of ATP and NADH. 
(cipB-LFC-LFA) have been shown to have beneficial effects on performance, nutrient digestibility, intestinal morphology as well as intestinal and fecal microflora. Their activities are summarized in Table 1.

\section{Antimicrobial peptides can promote the performance of pigs}

Antimicrobial lactoferrin peptides are one of the most prevalent AMPs used in swine nutrition. It has been demonstrated that dietary supplementation with recombinant lactoferrampin-lactoferricin (produced by the Institute of Subtropical Agriculture, Chinese Academy of Science which obtained through the expression of the lactoferampin-lactoferricin gene in the expression host P. pastoris (KM71) XS10 [16]) increased the final body weight and the average daily gain (ADG) of piglets by 13.3 and $29.3 \%$, respectively while decreasing feed conversion by $11.5 \%[16,17]$. Tang et al. [16,17] showed that piglets supplemented with cipB-LFC-LFA had higher ADG and ADFI than pigs fed control diets A mixture of AMPs including lactoferrin, cecropin, defensin, and plectasin was shown to enhance ADG, ADFI and G:F on 5 farms [18]. Growth promoting effects of the antimicrobial peptides A3 and P5 were also observed [4]. Increasing the levels of dietary AMP-A3 from 0 to $90 \mathrm{mg} / \mathrm{kg}$ in diets linearly improved ADG [19] while dietary supplementation with $60 \mathrm{mg} / \mathrm{kg}$ AMP-P5 increased ADG, ADFI and G:F [4], but the effects of AMP-A3 or P5 did not surpass that of a positive control treatment supplemented with $150 \mathrm{mg} / \mathrm{kg}$ avilamycin [20].

Dietary inclusion of Colicin E1 had a significant effect on pig performance in that pigs fed the control diet gained an average of $380 \mathrm{~g}$, while pigs receiving 11 and $16.5 \mathrm{mg}$ Colicin E1 per kg of diet gained 540 and $940 \mathrm{~g}$, respectively [21]. However, the joint use of antibacterial peptide and $\mathrm{Zn}$-Met did not show any synergistic effects on pig performance [22].

The effects of AMPs on performance can be explained on the basis of their antimicrobial activity. For example, Colicins E1 and $\mathrm{N}$ have been shown to inhibit the activities of $E$. coli strains that caused post-weaning diarrhea and edema disease in pigs [23]. The improvement in performance can also be related to improvements in nutrient digestibility $[4,20,24]$. Yoon et al. $[4,19,20]$ found that pigs diets supplemented with AMP-A3 or P5 showed an increase in the apparent total tract digestibility of dry matter, crude protein and gross energy.

\section{Antimicrobial peptides can enhance the immune status of pigs}

AMPs are important components of the host's defense system and are effector molecules of innate immunity with direct antimicrobial and immune mediator function $[2,25,26]$. Tang et al. [5] found that dietary supplementation with cipB-lactoferricin-lactoferrampin increased serum IgA and IgG but reduced serum IgM. The researchers from National Feed Engineering Technology Research Center (Beijing, China) prepared antimicrobial peptide cecropin AD using cecropin A and cecropin D isolated from the silkworm Hyalophora cecropia and added it to weaned piglets challenged with $E$. coli [27]. The results show that cecropin AD could increase levels of secretory IgA in jejunum and serum IgA, IgG, interleukin-1 $\beta$ and interleukin-6 [27]. AMPs can influence the adaptive immune system, either directly or indirectly via alteration of the gut microflora [5]. This was confirmed by results showing that dietary AMP-A3 or P5 decreased fecal Clostridium spp. and coliforms, as well as decreasing ileal and cecal total anaerobic bacteria, Clostridium spp. and coliforms [20].

\section{Antimicrobial peptides can improve the intestinal health of pigs}

A toxin produced by pathogenic bacteria in the gut can cause inflammation of the intestinal mucosa and diarrhea associated with morphological changes in the small intestine, such as shortening of the villi and an increase in crypt depth [28]. The antibacterial action of AMPs provides an effective support for normal intestinal morphology and function. Tang et al. [5] found that lactoferrampin-lactoferricin increased the height of the villi in the jejunum and ileum as well as the villus height: crypt depth ratio in the jejunum and ileum, which may be related to the fact that LFC-LFA can decrease the concentration of E. coli and increase lactobacilli and bifidobacteria in the gut. Similar results were observed in pigs following AMP-A3 [19] or cecropin AD [27] treatment. In addition, dietary supplementation with AMPs induced lower serum D-lactate concentrations [17] that increased intestinal permeability and enhanced the efficiency of absorption and utilization of nutrients.

\section{Antimicrobial peptides alleviate the toxic effects of deoxynivalenol (DON) in pigs}

Recently, we found that AMPs played a protective effect in piglets challenged with DON [29]. The composite antimicrobial peptide GLAM $^{\circledR} 180 \#$ used in our studies contains antibacterial lactoferrin peptides, plant defensins and active yeast and these three bioactive components have been shown to have a positive effect on growth and health of animals. Feeding 0.4\% GLAM ${ }^{\circledR} 180 \#$ to piglets challenged with diets containing $4 \mathrm{mg} / \mathrm{kg}$ DON improved overall feed efficiency (Table 2), promoted blood circulation, alleviated organ damage, and reduced DON toxicity [29]. 


\section{Antimicrobial peptide and dose}

Antimicrobial peptide-A3 (AMP-A3); 60 or $90 \mathrm{mg} / \mathrm{kg}$

Antimicrobial peptide-P5 (AMP-P5); 40 or $60 \mathrm{mg} / \mathrm{kg}$

Synthetic antimicrobial peptide-A3 or P5 (AMP-A3 and P5); 60 mg AMP-A3 or

$60 \mathrm{mg}$ AMP-P5/kg

Antimicrobial peptide colicin $\mathrm{E} 1$; 11 or $16.5 \mathrm{mg} / \mathrm{kg}$

Antimicrobial peptide cecropin AD; 400 mg/kg

cipB-lactoferricin-lactoferrampin (cipB-LFC-LFA) $100 \mathrm{mg} / \mathrm{kg}$

Recombinant Lactoferrampin-Lactoferricin; $100 \mathrm{mg} / \mathrm{kg}$

Composite antimicrobial peptides (CAP, consist mainly of antibacterial lactoferrin peptides, along with plant defensins and active yeast); $400 \mathrm{mg} / \mathrm{kg}$ mainly of antibacterial lactoferrin peptides, along

with plant defensins and active yeast); $400 \mathrm{mg} / \mathrm{kg}$

Composite antimicrobial peptides (CAP, consist mainly of antibacterial lactoferrin peptides, along with plant defensins and active yeast); $400 \mathrm{mg} / \mathrm{kg}$

A mixture of lactoferrin, cecropin, defensin, and plectasin $+3.0 \mathrm{~g} / \mathrm{kg}$ of AMPs for 32 days
Weanling piglets fed with basal diet $+1.5 \mathrm{~g}$ apramycin $/ \mathrm{kg}$ diet and basal diet supplemented with 0,60 and $90 \mathrm{mg}$ AMP-A3/kg diet in 2 phases (d 0-14 post-weaning: $14.28 \mathrm{MJ} / \mathrm{kg} \mathrm{ME}$ and $15.5 \mathrm{~g} / \mathrm{kg}$ lysine; d 15-28 post-weaning: $14.11 \mathrm{MJ} / \mathrm{kg} \mathrm{ME}$ and $13.5 \mathrm{~g} / \mathrm{kg}$ lysine)

Weanling piglets fed with basal diet, basal diet $+1.5 \mathrm{~g} / \mathrm{kg}$ apramycin basal diet $+40 \mathrm{mg} / \mathrm{kg}$ AMP-P5 and basal diet $+60 \mathrm{mg} / \mathrm{kg}$ AMP-P5 in 2 phases (d 0-14 post-weaning: $14.28 \mathrm{MJ} / \mathrm{kg} \mathrm{ME}$ and $15.5 \mathrm{~g} / \mathrm{kg}$ lysine; $\mathrm{d}$ 15-28 post-weaning: $14.11 \mathrm{MJ} / \mathrm{kg} \mathrm{ME}$ and $13.5 \mathrm{~g} / \mathrm{kg}$ lysine)

Weanling piglets fed with basal diet, basal diet $+150 \mathrm{mg} / \mathrm{kg}$ avilamycin basal diet $+60 \mathrm{mg} / \mathrm{kg}$ AMP-A3 and basal diet $+60 \mathrm{mg} / \mathrm{kg}$ AMP-P5 for 28 days

Weaned pigs fed with diets containing 0,11 , or $16.5 \mathrm{mg}$ colicin E1/kg diet and were orally inoculated with $1 \times 10^{9} \mathrm{CFU}$ of each of two F18-positive $E$ coli strains

Weaned barrows fed with basal diet or similar diets supplemented with antibiotics (100 mg/kg kitasamycin plus $800 \mathrm{mg} / \mathrm{kg}$ colistin sulfate) or $400 \mathrm{mg} / \mathrm{kg}$ cecropin $\mathrm{AD}$ and were orally challenged with $10^{9} \mathrm{CFU} / \mathrm{mL}$ of E. coli K88

Weanling piglets were challenged with enterotoxigenic E. coli and randomly assigned to four treatment groups fed a maize-soyabea meal diet containing either no addition, cipB at $100 \mathrm{mg} / \mathrm{kg}$, cipB-LFC

LFA at $100 \mathrm{mg} / \mathrm{kg}$ or colistin sulfate at $100 \mathrm{mg} / \mathrm{kg}$ for 3 weeks

Weanling piglets fed with basal diet, basal diet $+0.1 \mathrm{~g} / \mathrm{kg}$ lactoferrampin-lactoferricin and basal diet $+0.1 \mathrm{~g} / \mathrm{kg}$ chlortetracycline for 21 days

Weanling piglets fed with basal diet, basal diet $+0.4 \%$ CAP, basal diet + $4 \mathrm{mg} / \mathrm{kg}$ deoxynivalenol, and basal diet $+4 \mathrm{ppm}$ deoxynivalenol $+0.4 \%$

$4 \mathrm{mg} / \mathrm{kg}$ deoxynivalenol, and basal diet $+4 \mathrm{ppm}$ deoxynivalenol $+0.4 \%$ CAP for 30 days

Weanling piglets fed with basal diet, basal diet $+0.4 \%$ CAP, basal diet + $4 \mathrm{mg} / \mathrm{kg}$ deoxynivalenol, and basal diet $+4 \mathrm{ppm}$ deoxynivalenol $+0.4 \%$ CAP for 30 days

Pigs fed with basal diet, basal diet $+2.0 \mathrm{~g} / \mathrm{kg}$ of AMPs and basal diet

\section{Application effects}

References

Has beneficial effects on performance, total tract apparent digestibility of nutrients, intestinal

morphology and intestinal and fecal microflora

Improves the performance and apparent total tract digestibility of nutrients and reduces

coliforms

Improves the performance, nutrient digestibility, intestinal morphology and to reduces pathogenic bacteria

Improves the performance, reduces incidence of postweaning diarrhe

Enhances pig performance through increasing

immune status and nitrogen and energy

Yoon et al. $2013[4]$

Yoon et al. 2014 [20]

Cutler et al. 2007 [21]

Wu et al. 2012 [27]

Improves performance through an antibacterial effect, the regulation of immune function, improvement of the absorption of Fe and a reduction in the incidence of diarrhea

Improves performance and affects serum parameters

Tang et al. 2009 [5]

Tang et al. 2012 [17]

Improves feed efficiency, immune function, and antioxidation capacity and alleviates organ damage

Improves intestinal morphology and intestinal epithelial cell proliferation and protein synthesis; May repair the intestinal injury induced by DON

Attenuate the metabolic disturbances in AA, lipid, Xiao et al. 2015 [31] and energy metabolism induced by DON.

Improves performance, reduces the incidence of diarrhea, and increases the survival rate of weaned pigs 
Table 2 Effects of composite antimicrobial peptides on the performance of piglets $(12-26 \mathrm{~kg})$ challenged with deoxynivalenol ${ }^{1,2}$

\begin{tabular}{lllll}
\hline Item & \multicolumn{3}{c}{ Diets } & SEM \\
\cline { 2 - 5 } & NC & CAP & DON & DON + CAP
\end{tabular}

\begin{tabular}{lllllll}
\hline ADG, kg & & & & & & \\
Day 0 to 15 & 0.32 & 0.24 & 0.30 & 0.30 & 0.01 & 0.09 \\
Day 15 to 30 & $0.64^{\mathrm{a}}$ & $0.66^{\mathrm{a}}$ & $0.40^{\mathrm{b}}$ & $0.48^{\mathrm{b}}$ & 0.02 & $<0.01$ \\
Day 0 to 30 & $0.48^{\mathrm{a}}$ & $0.45^{\mathrm{a}}$ & $0.35^{\mathrm{b}}$ & $0.39^{\mathrm{b}}$ & 0.01 & $<0.01$ \\
ADFl, kg & & & & & & \\
Day 0 to 15 & $0.67^{\mathrm{a}}$ & $0.56^{\mathrm{b}}$ & $0.68^{\mathrm{a}}$ & $0.63^{\mathrm{ab}}$ & 0.02 & 0.02 \\
Day 15 to 30 & $1.33^{\mathrm{a}}$ & $1.10^{\mathrm{b}}$ & $1.07^{\mathrm{b}}$ & $1.04^{\mathrm{b}}$ & 0.03 & $<0.01$ \\
Day 0 to 30 & $1.00^{\mathrm{a}}$ & $0.83^{\mathrm{b}}$ & $0.87^{\mathrm{b}}$ & $0.84^{\mathrm{b}}$ & 0.02 & $<0.01$ \\
G:F & & & & & & \\
Day 0 to 15 & 0.47 & 0.42 & 0.44 & 0.49 & 0.02 & 0.54 \\
Day 15 to 30 & $0.49^{\mathrm{b}}$ & $0.61^{\mathrm{a}}$ & $0.38^{\mathrm{c}}$ & $0.47^{\mathrm{bc}}$ & 0.02 & $<0.01$ \\
Day 0 to 30 & $0.48^{\mathrm{ab}}$ & $0.55^{\mathrm{a}}$ & $0.40^{\mathrm{b}}$ & $0.47^{\mathrm{a}}$ & 0.01 & $<0.01$ \\
\hline
\end{tabular}

Xiao et al. 2013 [29].

${ }^{1} \mathrm{NC}$ : Basal diet. CAP: Basal diet $+0.4 \%$ composite antimicrobial peptide, DON: Basal diet $+4 \mathrm{mg} / \mathrm{kg}$ DON, DON + CAP: Basal diet + $4 \mathrm{mg} / \mathrm{kg}$ DON + 0.4\% composite antimicrobial peptide.

${ }^{2} n=7$. ${ }^{a-c}$ Values with different letters within the same row are significantly different $(P<0.05)$

As indicators of intestinal morphology and function, the serum D-lactate and diamine oxidase content were lower but the villous height/crypt depth (Table 3) and the proliferating cell nuclear antigen (PCNA) labeling indexes in the jejunum and ileum were greater in piglets fed DON + GLAM ${ }^{\circ} 180 \#$ treatments than those in the DON treatment alone. In addition, GLAM ${ }^{\circ} 180 \#$ increased the protein levels of phosphorylated Akt, mTOR and 4E-binding protein 1 in the jejunum of piglets. The results indicate that GLAM $^{\circ} 180 \#$ improved intestinal morphology and promoted intestinal epithelial cell proliferation and protein synthesis [30]. The combined results of ${ }^{1} \mathrm{H}-\mathrm{NMR}$ and LC-MS/MS showed the serum concentrations of HDL, unsaturated lipids, proline, citrate and fumarate were greater while those of glycoprotein, urea, TMAO, glycine and lactate were lower, in the DON + CAP group compared to those in the DON group, which indicated GLAM ${ }^{\circ} 180 \#$ could attenuate the metabolic disturbances in AA, lipid, and energy metabolism induced by DON [31]. The application of AMPs in DON challenged piglets demonstrates that GLAM $^{\oplus} 180$ \# can alleviate the toxic effect of DON on pigs.

\section{Conclusions}

Due to their broad spectrum of activity against several species of bacteria, fungi, protozoa, and enveloped virus, AMPs show beneficial effects on performance, nutrient digestibility, intestinal morphology as well as intestinal and fecal microflora in pigs. With the development of technology, the cost of addition of AMPs is gradually reduced, especially in swine production. Although most AMPs did not provide equal effects to that of antibiotics in swine nutrition, they have considerable potential as an alternative for antibiotics in rations fed to swine.

Table 3 Effects of composite antimicrobial peptides on the jejunal and ileal morphology of piglets challenged with deoxynivalenol ${ }^{1,2}$

\begin{tabular}{|c|c|c|c|c|c|c|}
\hline \multirow[t]{2}{*}{ Item } & \multicolumn{4}{|c|}{ Diets } & \multirow[t]{2}{*}{ SEM } & \multirow[t]{2}{*}{$P$-value } \\
\hline & NC & CAP & DON & $\mathrm{DON}+\mathrm{CAP}$ & & \\
\hline \multicolumn{7}{|l|}{ Jejunum } \\
\hline Villus height, $\mu \mathrm{m}$ & 240.01 & 239.08 & 197.56 & 221.87 & 7.05 & 0.23 \\
\hline Crypt depth, $\mu \mathrm{m}$ & $126.39^{\mathrm{ab}}$ & $117.03^{b}$ & $145.14^{\mathrm{a}}$ & $110.48^{b}$ & 6.88 & 0.04 \\
\hline Villus height: Crypt depth & 1.92 & 2.06 & 1.39 & 2.05 & 0.11 & 0.08 \\
\hline Goblet cell number & 11.50 & 11.00 & 17.67 & 12.00 & 1.20 & 0.26 \\
\hline Lymphocyte number & $195.00^{b}$ & $198.50^{b}$ & $256.33^{\mathrm{a}}$ & $204.50^{b}$ & 9.26 & $<0.01$ \\
\hline \multicolumn{7}{|l|}{ Ileum } \\
\hline Villus height, $\mu \mathrm{m}$ & $263.20^{\mathrm{a}}$ & $240.15^{\mathrm{a}}$ & $170.98^{\mathrm{b}}$ & $185.08^{b}$ & 10.31 & $<0.01$ \\
\hline Crypt depth, $\mu \mathrm{m}$ & 117.73 & 120.05 & 109.45 & 104.73 & 4.36 & 0.56 \\
\hline Villus height: Crypt depth & $2.32^{\mathrm{a}}$ & $2.06^{\mathrm{ab}}$ & $1.57^{c}$ & $1.81^{\mathrm{ab}}$ & 0.09 & 0.04 \\
\hline Goblet cell number & 22.33 & 16.00 & 19.00 & 18.50 & 1.36 & 0.38 \\
\hline Lymphocyte number & $181.25^{c}$ & $154.75^{d}$ & $232.00^{\mathrm{a}}$ & $204.00^{b}$ & 7.70 & $<0.01$ \\
\hline
\end{tabular}

Xiao et al. 2013 [30].

${ }^{1} \mathrm{NC}$ : Basal diet. CAP: Basal diet $+0.4 \%$ composite antimicrobial peptide, DON: Basal diet + $4 \mathrm{mg} / \mathrm{kg} \mathrm{DON}$, DON + CAP: Basal diet + $4 \mathrm{mg} / \mathrm{kg}$ DON + 0.4\% composite antimicrobial peptide.

${ }^{2} n=7$. ${ }^{\text {a-d }}$ Values with different letters within the same row are significantly different $(P<0.05)$. 


\section{Competing interests}

The authors declare they have no competing interests.

\section{Authors' contributions}

HX, FYS, MMW, WKR, BET, and YLY collected papers and drafted the manuscript. HX, FYS, and BET co-wrote the paper: All authors read and approved the final manuscript.

\section{Authors' information}

Hao xiao and Fangyuan Shao are joint first authors.

\section{Acknowledgement}

This work was supported by the National Natural Science Foundation of China (No. 31330075; 31372326).

\section{Author details}

${ }^{1}$ Observation and Experiment Station of Animal Nutrition and Feed Science in South-Central China, Ministry of Agriculture, Hunan Provincial Engineering Research Center for Healthy Livestock and Poultry Production, Key Laboratory of Agro-ecological Processes in Subtropical Region, Institute of Subtropical Agriculture, Chinese Academy of Sciences, Changsha, Hunan 410125, China. ${ }^{2}$ University of the Chinese Academy of Sciences, Beijing 10008, China. ${ }^{3}$ Department of Microbiology, Molecular Genetics, and Immunology, University of Kansas Medical Center, Kansas City, KS 66160, USA. ${ }^{4}$ Hubei Collaborative Innovation Center for Animal Nutrition and Feed Safety, Wuhan Polytechnic University, Wuhan 430023, China.

Received: 8 November 2014 Accepted: 21 April 2015

\section{Published online: 07 May 2015}

\section{References}

1. Diez-Gonzalez F. Applications of bacteriocins in livestock. Curr Issues Intest Microbiol. 2007:8:15-23.

2. Reddy KV, Yedery RD, Aranha C. Antimicrobial peptides: premises and promises. Int J Antimicrob Agents. 2004;24:536-47.

3. Wang Y, Lu Z, Feng F, Zhu W, Guang H, Liu J, et al. Molecular cloning and characterization of novel cathelicidin-derived myeloid antimicrobial peptide from Phasianus colchicus. Dev Comp Immunol. 2011;35:314-22.

4. Yoon JH, Ingale SL, Kim JS, Kim KH, Lohakare J, Park YK, et al. Effects of dietary supplementation with antimicrobial peptide-P5 on growth performance, apparent total tract digestibility, faecal and intestinal microflora and intestinal morphology of weanling pigs. J Sci Food Agric. 2013:93:587-92.

5. Tang Z, Yin Y, Zhang Y, Huang R, Sun Z, Li T, et al. Effects of dietary supplementation with an expressed fusion peptide bovine lactoferricinlactoferrampin on performance, immune function and intestinal mucosal morphology in piglets weaned at age 21 d. Br J Nutr. 2009;101:998-1005.

6. Bahar AA, Ren D. Antimicrobial peptides. Pharmaceuticals. 2013;6:1543-75.

7. Wang G. Improved methods for classification, prediction, and design of antimicrobial peptides. Methods Mol Biol. 2015;1268:43-66.

8. Guilhelmelli F, Vilela N, Albuquerque P, Derengowski Lda S, Silva-Pereira I, Kyaw CM. Antibiotic development challenges: the various mechanisms of action of antimicrobial peptides and of bacterial resistance. Front Microbiol. 2013:4:353.

9. Yang L, Harroun TA, Weiss TM, Ding L, Huang HW. Barrel-stave model or toroidal model? A case study on melittin pores. Biophys J. 2001;81:1475-85.

10. Pouny $Y$, Rapaport D, Mor A, Nicolas $P$, Shai $Y$. Interaction of antimicrobial dermaseptin and its fluorescently labeled analogues with phospholipid membranes. Biochemistry. 1992;31:12416-23.

11. Rotem S, Mor A. Antimicrobial peptide mimics for improved therapeutic properties. Biochim Biophys Acta. 2009;1788:1582-92.

12. Li Y, Xiang Q, Zhang Q, Huang Y, Su Z. Overview on the recent study of antimicrobial peptides: origins, functions, relative mechanisms and application. Peptides. 2012;37:207-15.

13. Mayor S, Pagano RE. Pathways of clathrin-independent endocytosis. Nat Rev Mol Cell Biol. 2007;8:603-12.

14. Boman HG, Agerberth B, Boman A. Mechanisms of action on Escherichia coli of cecropin P1 and PR-39, two antibacterial peptides from pig intestine. Infect Immun. 1993;61:2978-84.

15. Scheit KH, Reddy ES, Bhargava PM. Seminaplasmin is a potent inhibitor of E. coli RNA polymerase in vivo. Nature. 1979;279:728-31.
16. Tang XS, Tang ZR, Wang SP, Feng ZM, Zhou D, Li TJ, et al. Expression, purification, and antibacterial activity of bovine lactoferrampin-lactoferricin in Pichia pastoris. Appl Biochem Biotechnol. 2012;166:640-51.

17. Tang X, Fatufe AA, Yin YL, Tang ZR, Wang SP, Liu ZQ, et al. Dietary supplementation with recombinant lactoferrampin-lactoferricin improves growth performance and affects serum parameters in piglets. J Anim Vet Adv. 2012;11:2548-55.

18. Xiong $X$, Yang HS, Li L, Wang YF, Huang RL, Li FN, et al. Effects of antimicrobial peptides in nursery diets on growth performance of pigs reared on five different farms. Livestock Sci. 2014;167:206-10.

19. Yoon JH, Ingale SL, Kim JS, Kim KH, Lee SH, Park YK, et al. Effects of dietary supplementation of antimicrobial peptide-A3 on growth performance, nutrient digestibility, intestinal and fecal microflora and intestinal morphology in weanling pigs. Anim Feed Sci Technol. 2012;177:98-107.

20. Yoon JH, Ingale SL, Kim JS, Kim KH, Lee SH, Park YK, et al. Effects of dietary supplementation of synthetic antimicrobial peptide-A3 and P5 on growth performance, apparent total tract digestibility of nutrients, fecal and intestinal microflora and intestinal morphology in weanling pigs. Livestock Sci. 2014;159:53-60.

21. Cutler SA, Lonergan SM, Cornick N, Johnson AK, Stahl CH. Dietary inclusion of colicin e1 is effective in preventing postweaning diarrhea caused by F18-positive Escherichia coli in pigs. Antimicrob Agents Chemother. 2007:51:3830-5.

22. Wang JH, Wu CC, Feng J. Effect of dietary antibacterial peptide and zinc-methionine on performance and serum biochemical parameters in piglets. Czech J Anim Sci. 2011;56:30-6.

23. Stahl CH, Callaway TR, Lincoln LM, Lonergan SM, Genovese KJ. Inhibitory activities of colicins against Escherichia coli strains responsible for postweaning diarrhea and edema disease in swine. Antimicrob Agents Chemother. 2004;48:3119-21.

24. Dubos RJ. Studies on a bactericidal agent extracted from a soil bacillus: li. Protective effect of the bactericidal agent against experimental pneumococcus infections in mice. J Exp Med. 1939;70:11-7.

25. Peters BM, Shirtliff ME, Jabra-Rizk MA. Antimicrobial peptides: primeval molecules or future drugs? PLoS Pathog. 2010;6:e1001067.

26. Beisswenger $C$, Bals R. Functions of antimicrobial peptides in host defense and immunity. Curr Protein Pept Sci. 2005;6:255-64.

27. Wu S, Zhang F, Huang Z, Liu H, Xie C, Zhang J, et al. Effects of the antimicrobial peptide cecropin AD on performance and intestinal health in weaned piglets challenged with Escherichia coli. Peptides. 2012;35:225-30.

28. Swidsinski A, Ladhoff A, Pernthaler A, Swidsinski S, Loening-Baucke V, Ortner $\mathrm{M}$, et al. Mucosal flora in inflammatory bowel disease. Gastroenterology. 2002;122:44-54.

29. Xiao H, Wu MM, Tan BE, Yin YL, Li TJ, Xiao DF, et al. Effects of composite antimicrobial peptides in weanling piglets challenged with deoxynivalenol: I. Growth performance, immune function, and antioxidation capacity. J Anim Sci. 2013;91:4772-80.

30. Xiao H, Tan BE, Wu MM, Yin YL, Li TJ, Yuan DX, et al. Effects of composite antimicrobial peptides in weanling piglets challenged with deoxynivalenol: II. Intestinal morphology and function. J Anim Sci. 2013;91:4750-6.

31. Xiao H, Xiao H, Wu MM, Tan B, Li T, Ren WK, et al. Metabolic profiles in the response to supplementation with composite antimicrobial peptides in piglets challenged with deoxynivalenol. J Anim Sci. 2015;93:1114-23. 